Original Research Paper

\title{
Academic Motivation to Learn English in a Malaysian private University
}

\author{
Ahmed Fahim Youssef \\ Department of Education, SEGi University, Malaysia
}

Article history

Received: 13-06-2016

Revised: 25-11-2016

Accepted: 15-12-2016

Email: afy0123@gmail.com

\begin{abstract}
Motivation is accepted as one of the key factors in promoting second language teaching and learning. The study is based on the Self Determination Theory (SDT) developed by Deci and Ryan who were greatly interested in both the quantity and the quality of motivation. They categorized motivation from the unmotivated to the motivated and in between there are many levels of motivation. This study investigated 230 trainee teachers' Academic Motivation (AM) to learn in English in terms of gender, nationality, ethnic group, specialization and years of study at the Faculty of Education in a Malaysian private university. The results revealed that participants were significantly different in their Academic motivation based on their specialization and the period they spent in the Faculty of Education. There were no significant differences based on gender or nationality. Significant differences were noticed among participants from different ethnic groups in Intrinsic Motivation. Building on the findings a better understanding of trainee teachers' cognitive abilities, attitudes about self and university, as well as their language skills would help in improving their Academic Motivation to learn English. Providing opportunities to learn English outside the classroom through English language clubs, journeys to English speaking countries, debates, drama, songs and free writing competitions can help motivate them away from traditional classroom activities. Furthermore, communication between faculty and home is important to better understand the factors that may affect trainee teachers' Academic motivation to learn English.
\end{abstract}

Keywords: Academic Motivation, English Language Learning, Self Determination Theory, Intrinsic Motivation, Extrinsic Motivation

\section{Introduction}

\section{Background of the Study}

"Malaysia is one of the most multiethnic and multilingual countries in Southeast Asia" (Choi, 2008, p.14). Although ethnic languages are widely used in the country, English was the medium of education for most of private schools during the British rule. Many recent researchers focused on the cultural and ethnic factors affecting English language learning. Jou (2012), stated that language is not only a means of communication but also a symbol of an individual's identity and cultural background. British curriculum was mainly designed to serve their colonising authority and had no reflection on the Malaysian context (Gill, 2005). After independence, national unity was the most critical goal of the new rulers of Malaysia. In 1957, Malay medium primary schools renamed to be national schools while English, Chinese and Tamil schools became national-type schools. Bahasa Melayu (Malay language) was a compulsory subject for all schools but English remained as one of the essential languages used in the country. The new socio-economic policy during the 70 and $80 \mathrm{~s}$ of the twentieth century emphasized the integrity of all the components of the society (Ida Fatimawati, 2012). After four decades of replacing English by the national language, the importance of English was recognized as a tendency towards globalization was the main feature of the Malaysian Educational Policy during the last decade of the twentieth century. New concepts such as "development-oriented nationalism" and "knowledge economy" were introduced by the government to serve the new policy. English was reinstated as the medium of 
instruction for some subjects in secondary schools and for most subjects at higher education (Gill, 2005, p.250). Unfortunately, teaching of science and mathematics in English at the primary and secondary schools faced many difficulties related to the efficiency of teachers which affected the competence of students. Inspired by Malaysia Educational Blueprint (2013-2025), Institutions of Higher Education "play an important role in training the people necessary for the academic as well as the manpower needs of the nation" (Law of Malaysia, 2006, p.84). English proficiency was a still the key to join university as it is the medium of instruction in most Malaysian public and private universities (Ida Fatimawati, 2012). English was made one of the requirements for applying to higher education. Students were required to pass many types of national assessments to continue their learning after secondary school. The Malaysian Certificate of Education (SPM) was required to move on to form six, Malaysian Higher School Certificate (STPM), which is the Malaysian equivalent of the Cambridge A-level Examination and students who prefer to join public universities need to pass The Malaysian University English Test (MUET).

In spite of the high importance of English language teaching and learning stated in the Malaysia Educational Blueprint (2013-2025), the outcomes of language learning are not supportive as $64 \%$ of students applying for a place in tertiary education scored low or very low in the Malaysian University English Test (MUET) (MGBSLN, 2015). Studies on students who were exposed to English for 11 years in primary and secondary schools, showed that they still have difficulties related to language proficiency (Ida Fatimawati, 2012) and their written English was under satisfactory level (Mahady, 2010). In addition to that, the limited opportunities to use English outside the classroom widened the proficiency gap between students joining tertiary education from urban and rural areas where English is regarded as a foreign language (Gill, 2005). Apart from that trainee teachers' Academic Motivation (AM) to learn English is not given the due concern and the factors affecting their low motivation to learn English were not investigated in detail within the Malaysian context.

\section{Review of related Literature}

\section{Motivation}

As proposed in his Motivation and Personality, Maslow rejected the drive theory of Freud in the early 1930s saying that we cannot generalize the findings from experiments done on laboratory animals to people. Unlike drives of motivation for animals which can be easily met, these drives are endless for humans and never experienced to be met. Maslow's Hierarchy of Needs then came to play a big role in the field of understanding human needs (Maslow, 1970). At the lowest level of the pyramid, he placed biological needs for food, clothing and shelter. Then, he put safety, need for employment, security for self and family. The third level of the pyramid is belongingness and love followed by the need to achieve reputation and strength. The fifth and highest level of human needs is the need for self-actualization.

This part of the current study is devoted to review in brief some theories of motivation in education that can be arranged into three main periods. (i) The social psychological period, (ii) The cognitive situated period and (iii) The process-oriented period. Each period has a number of theories introduced by pioneers in the fields of linguistics, sociolinguistics and second language acquisition. The expectancy-value theories developed by Eccles (1983), are considered the beginning of introducing motivation theories in the field of education. Gardner's socio-educational theory is considered a milestone in the research of language learning motivation (Dornyei, 1994). Let's have a look at some examples of these theories.

\section{Gardner's Socio-Educational Theory}

Gardner and his associates were concerned with investigating attitudes influencing the success in Second language (Gardner and Lambert, 1972). Gardner argued that learners were motivated to learn second language (L2) to communicate with the L2 communities and to behave like them (Masgoret and Gardner, 2003). For Gardner and Lambert (1972) integrative orientation made students exert more effort than instrumental motivation. Rubenfeld et al. (2007) stated that the integrative motive includes three components: Integrativeness, attitudes toward the learning situation and motivation.

\section{Goal Theories}

Goal theories empower human behaviour by goals. By modifying these goals, "the quality and intensity" of individuals' behaviour changes in return (Covington, 2000, 174). Kaplan and Maehr (2007) proposed that goal achievement is much related to a competence-relevant setting. Another version of goal theories is academic goals which is described as learning versus performance goals theory (Thrash and Elliot, 2002). Researchers argued that learners focus on refining their skills and competence, willing to do difficult tasks, eager to face challenges and overcome risks. They prefer higher cognitive skills not simple thinking strategies. Even though they ask for help, they are keen on completing the tasks themselves and they are intrinsically motivated about school and learning.

\section{The Self-Determination Theory}

Self-determination theory is based on a strong theoretical background and has been discussed empirically in educational settings by (Deci and Ryan, 
2000; Crookes and Schmidt, 1991; Dornyei, 1994). Selfdetermination theory addresses the quantity as well as the quality of motivation. Intrinsic motivation was defined as the human tendency toward learning and creativity affected by social values and extrinsic incidents and integrating them into their personal values and self-motives. The Self-determination theory is based on four mini-theories: (i) Basic needs, (ii) cognitive evaluation, (iii) organismic integration and (iv) causal orientations (Ryan and Deci, 1989). The Basic Needs Theory suggests that autonomy, competence and relatedness inspire people's motivation to act. The Cognitive Evaluation Theory states that events have three aspects: Informational, controlling and motivating. These aspects interact to foster intrinsic and extrinsic motivation. In The Organismic Integration theory, Ryan and Deci, (1989) suggested that to successfully cope with the environment, individuals have to go through an internalization process to bring external values in. The Causality Orientations Theory tries to give explanations about the differences in the ways people interpret and act with motivational powers (Ryan and Deci, 1989). The first application of self-determination theory in educational contexts was by Vansteenkiste et al. (2006). Vallerand and his associates extended the research on perceptions of intrinsic motivation to other related factors in the learning processes.

\section{Basic Needs Theory (BNT)}

Ryan and Deci (2000), described intrinsic motivation as 'the inherent tendency to seek out novelty and challenges, to extend and exercise one's capacities, to explore and to learn". Researchers who studied human behaviour argued that young children are naturally active, curious and motivated to explore and play even though they are not rewarded. This inherited motivation in children needs supportive conditions to survive and develop (Deci and Ryan, 1985). They conducted a lot of laboratory experiments to find out the factors and conditions that support or undermine intrinsic motivation with a great focus on human psychological needs to be competent and to achieve autonomy. The findings showed that positive feedback and reward enhance and support intrinsic motivation and sense of autonomy (Deci, 1975). Supported by the findings of Ryan and Deci (2000), the interest of researchers in SDT gradually moved to focus on autonomous and controlled types of motivation. He claimed that there was a negative effect of locus or reward on intrinsic motivation while the effect of choices and self-directed behaviour supported intrinsic motivation as they allow people to have a great deal of autonomy (Deci and Ryan, 1985).

\section{Cognitive Evaluation Theory (CET)}

The theory proposed that external factors such as tangible rewards, deadlines, surveillance, negative feedback and evaluations seem to lessen autonomous satisfaction and undermined intrinsic motivation. While providing choice in activities engagement and positive feedback facilitated intrinsic motivation. Tangible extrinsic rewards like salary did not undermine intrinsic motivation as being independent from the activity. In addition to that, negative feedback was reported to decrease both intrinsic and extrinsic motivation (Deci and Ryan, 1985). It was also argued in a later study that social-contextual factors that are supportive of autonomy and competence promote intrinsic motivation (Gagné and Deci, 2005).

\section{Organismic Integration Theory (OIT)}

Organismic Integration Theory attempted to bring all types of regulation with detailed explanation of the nature of each of them. The most non-self-determined or amotivation falls on the left while the most selfdetermined or intrinsic motivation falls on the right. Amotivation can be described as the state in which there is no motivation at all or the person has no intention to behave. External regulation refers to the type of motivation that is driven by a locus of initiation which is external by offering a reward or punishment. In other words, a student who finishes tasks at school seeking for a reward from a teacher or fearing to be penalized by parents is externally regulated which the lowest level of extrinsic motivation and is expected to decline in the absence of reward or punishment. Introjected regulation refers to the acceptance to perform a task without internalization or feeling a sense of relatedness to the activity.

\section{Causality Orientations Theory (COT)}

Causality orientations theory, suggests that people are not equal in their intrinsic or extrinsic motivation. There are three main scales to decide the level of orientation in motivation. The first is autonomous orientation when individual stake part in activities because they are naturally enjoyable, challenging and implanted with their permanent values. The second is controlled orientation as individuals are motivated because they expect some kind of reward or recognition from the group they live with. The third is impersonal orientations which are experienced when someone is motivated and not significantly related to any of the other two types of causality orientations (Deci and Ryan, 1985).

\section{Methodology}

\section{Research Design}

This study is a quantitative study where data were collected using a questionnaire to investigate Academic motivation to learn English among the students of the 
Faculty of Education in a private university located in Kota Damansara, Petaling Jaya, Selangor, Malaysia. The Faculty of Education offers four programs namely: (i) Teaching English as a Second Language, (ii) Early Childhood, (iii) Special Needs and (iv) Guidance and Counselling. In addition to these programs there is a Special Diploma in Early Childhood Education. The medium of instruction is mainly English but Bahasa Melayu is used for teaching some subjects. The faculty is following the Malaysian public policy of higher education in terms of degrees and regulations.

\section{Sample}

From 404 undergraduates studying at the Faculty of Education in a Malaysian University, 230 completed their questionnaires during the academic year 2015. Students are mostly Malaysian from different ethnic groups aged between 18 and 22 years old. To make sure that different ethnic groups and different majors were represented in the study, stratified random sampling was used.

\section{Instrumentation}

\section{Academic Motivation Scale (AMS)}

The Academic Motivation Scale (AMS), was developed by Stover et al. (2012). The scale has been applied in recent decades in high school as well as in college education (Stover et al., 2012). This scale presents seven constructs of the motivation scale and contains 28 items on a 100-point scale. The main constructs assessed are: (i) Intrinsic Motivation to know, (ii) Intrinsic Motivation towards accomplishment, (iii) Intrinsic Motivation to experience stimulation, (iv) Extrinsic Identified Motivation, (v) Extrinsic Introjected motivation, (vi) Extrinsic External Regulation and (vii) Amotivation.

\section{Data Collection Procedures}

The researcher was given the needed permission to conduct the research and arranged with lecturers the suitable time to distribute the questionnaires. The researcher asked lecturers to: (i) First, allow the researcher to give an idea about the study in classrooms and give detailed information about the research and assure confidentiality. (ii) Students who wanted to participate were given the set of questionnaires to fill in while those who refused to participate in the study stayed in their places. (iii) The researcher moved through the classrooms to make sure that students were not facing any difficulties with the questionnaires. The answers for all items took between fifteen and 25 minutes. From the distributed questionnaires, 230 students returned their questionnaires. The researcher checked them to make sure that the data collected were ready to be keyed in to The Statistical Package for Social Sciences (SPSS).

\section{Data Analysis}

First, the Statistical Package for Social Sciences (SPSS) version 20.0 was used. A probability level of $p=$ 0.05 or less was set as the criterion for accepting or rejecting a null hypothesis that there will be no significant differences among the groups.

\section{Validity and Reliability}

The researcher adapted the Academic Motivation scale from the original version introduced by Stover et al. (2012). The pilot study run by the researcher revealed that the language used in the original version was not suitable to the level of the participants. They seemed to be confused about some items. The researcher validated the changes with three of the lecturers teaching the participants. SPSS was used to run confirmatory factor analysis to make sure that the instrument was valid in the Malaysian context. Kaiser-Meyer-Olkin Measure of Sampling Adequacy (KMO) was (.830) and $p$ value was $(=<0.001)$. The instrument explained $(70.611 \%)$ of the variance and created five constructs. Two items were excluded as they were not related to any of the five components.

Cronbach's Alpha Reliability test was conducted and showed that the Academic Motivation questionnaire is reliable to be used in this study $(a=0.855)$.

\section{Discussion of Findings}

\section{Demographic Information Questions}

About 230 participants completed their questionnaires $(N=215,93.5 \%)$ were female while the male participants represented $(N=15,6.5 \%)$. This skewed distribution in the gender of participants is due to the small number of male students in the Faculty of Education $(N=26)$. Among the 215 female students there were 196 Malaysian participants $(85.21 \%)$ and 19 international female participants $(8.26 \%)$. Malaysian male students were $11(4.78 \%)$ and international male students were four participants $(1.73 \%)$. There were 96 (41.73\%) Chinese female students, 43(18.69\%) Indian female students and $52(22.60 \%)$ Malay students. 24 females $(10.43 \%)$ were not of the three main ethnic groups and represented at this study as "other". Male participants were ten Chinese $(4.34 \%)$, two Indian $(0.86 \%)$, one Malay $(0.43 \%)$ and two male students were not from any of the three main ethnic groups. Participants were all chosen from the. Those who were studying Teaching English as a Second Language (TESL) were 59 females and ten males $(30 \%)$. There were 56 females and two male students from Early Childhood Education (ECE) (25.21\%). Five female participants and one male were studying Counselling and Guidance (CGE). Participants who studied Teaching Students with Special Needs (SNE) were 
twelve females and one male. The biggest group came from Diploma of Early Childhood Education (DECE) as there were 83 females and one male. 42 participants said that they have spent less than one year in the Faculty of Education (18.26\%). 54 students said that they have been in the Faculty of Education for one year, $66(28.69 \%)$ spent two years, 42 spent three years and 26 participants were in the Faculty of Education for more than three years.

\section{Academic Motivation to Use English (AM)}

The results of overall Academic Motivation showed that $(N=10,4.3 \%)$ participants were highly motivated, $(N=156,67.8 \%)$ were moderate in their Academic Motivation and $(N=64,27.8)$ were low in their overall Academic Motivation. The results also revealed that $(N$ $=86,37.4 \%$ ) were high in their scores for Intrinsic Motivation, $(N=109,47.4 \%)$ were moderate, while $(N$ $=35,15.2 \%)$ were low in Intrinsic Motivation. In relation to Extrinsic Motivation, there were $(N=47$, $20.4 \%$ participants who were highly extrinsically motivated, $(N=125,54.3 \%)$ were moderate and $(N=$ $58,25.2 \%$ ) were low. The scores of Amotivation were reversed scores. That means the higher the scores, the lower the Academic Motivation. None of the participants was amotivated, $(N=7,3.04 \%)$ were moderate in their Amotivation, $(N=64,27.82 \%)$ were low in Amotivation and $(N=159,69.1 \%)$ were never amotivated.

\section{Academic Motivation and Gender}

Independent sample $t$-test was conducted to see if there were any significant differences between male and female students in terms of overall Academic Motivation. There was no statistically significant difference between male and female participants in Academic Motivation $(p=0.521)$ as well as for the other constructs of the scale.

\section{Academic Motivation and Nationality}

Independent sample t-test was conducted and showed that there was no significant difference between Malaysian and international participants in overall Academic Motivation $(F(228)=1.02, p=0.309)$. The test showed that there were no significant differences between the scores of Malaysian and international students in Intrinsic Motivation $(F(228)=0.35, p=$ 0.727), Extrinsic Motivation $(F(228)=1.121, p=$ $0.263)$, Amotivation $(F(228)=0.741, p=0.46)$, Intrinsic Motivation to know $(F(228)=-0.239, p=0.812)$, Intrinsic Stimulation $(F(228)=0.699, p=0.485)$, External Introjected Motivation, $(F(228)=0.822, p=$ $0.412)$, or External Regulation $(F(228)=0.953, p=$ 0.342 ). It can be concluded that both Malaysian and international students who participated in this study are almost the same in their level of Academic Motivation.

\section{Academic Motivation and Ethnic group}

One-way ANOVA test was conducted to figure out the significant differences among participants in their scores Academic Motivation AM. There was no significant difference in the scores of overall Academic Motivation $\operatorname{AM}(F(3,226)=1.615, p=0.187)$. The only significant difference was between Indians $(M=$ 83.1389, $S D=15.94251, p=0.05)$ and Chinese $(M=$ 75.0943, $S D=18.80642, p=0.05)$ participants in Intrinsic Motivation to know and accomplish.

\subsection{Academic Motivation and Specializations}

Results of the ANOVA test revealed that there was no significant difference between different specializations in overall Academic Motivation $(F(4,225)$ $=0.619,(p=0.649)$. There was a significant difference in Amotivation $(F(4,225)=3.404, p=0.10)$ between TESL $(M=14.7343, S D=11.14969, p=0.008)$ and $\operatorname{SNE}(M=$ $10.0, S D=0.0, p=0.008)$. The results for Amotivation also revealed that there was a significant difference between the scores of ECE $(M=13.4483, S D=8.4458, p$ $=0.028)$ and $\operatorname{SNE}(M=10.0, S D=0.0, p=0.028)$. A significant difference was noticed between Amotivation scores of DECE $(M=18.6111, S D=13.15349, p=$ $0.049)$ and $\operatorname{ECE}(M=13.4483, S D=8.4458, p=0.049)$. Finally, there was a significant difference in Amotivation between DECE $(M=18.6111, S D=13.15349, p=0.001)$ and SNE $(M=10.0, S D=0.0, p=0.001)$. The scores of Intrinsic motivation to know and accomplish were significantly different between TESL $(M=84.9819, S D=$ 15.46981, $p=0.001)$ and DECE $(M=72.7083, S D=$ $21.68785, p=0.001)$. The test showed that $\operatorname{SNE}(M=$ $88.3654, S D=12.60771, p=0.01)$ were significantly different from the DECE $(M=72.7083, S D=21.68785$, $p=0.01)$. The scores of Extrinsic Introjected Motivation were also significantly different between DECE $(M=$ 53.5714, $S D=24.96469, p=0.025)$ and TESL $(M=$ $40.8213, S D=26.07434, p=0.025)$. The ANOVA test also showed that TESL $(M=85.2899, S D=19.38169, p$ $=0.029)$ were significantly different in their Extrinsic External Regulation from DECE $(M=74.4048, S D=$ $25.19089, p=0.029)$. It can be concluded that DECE students were the least motivated in Amotivation scores, SNE participants were the most motivated to know and to accomplish, DECE students are the most motivated because they did not like to be blamed by others and TESL students are the most driven by external factors like salary and job.

\section{Academic Motivation and Period of Study}

One-way ANOVA was conducted to find out the significant differences among the different groups of participants based on the number of years they have studied at the Faculty of Education. There was a statistically significant difference in the overall Motivation $(F(4,225)=2.466, p=0.046)$. The one-way 
ANOVA test also showed that the difference was significant in Intrinsic Motivation $(F(4,225)=4.403, p$ $=0.002)$ as well as Amotivation $(F(4,225)=2.7, p=$ 0.032). Scores of participants were significantly different in Intrinsic Motivation to $\operatorname{Know}(F(4,225)=$ 2.726, $p=0.03)$ and in Intrinsic Stimulation $(F(4,225)$ $=4.007, p=0.004)$. There were no significant differences between participants in Extrinsic Motivation $(F(4,225)=0.68, p=0.606)$, External Introjected Motivation $(F(4,225)=1.158, p=0.33)$, or External Regulation $(F(4,225)=1.929, p=0.107)$.

The results revealed that there was a significant difference between the scores of students who spent less than one year and year two participants in Intrinsic Motivation $(p=0.028)$. As for Intrinsic Motivation, the difference was significant between those who spent less than one year and those who spent more than three years $(p=0.003)$. The researcher found significant difference between participants who spent more than year three and those who spent less than one year in Intrinsic Motivation to Know $(p=0.018)$. As for Intrinsic Stimulation, there was a significant difference between less than one year participants and year two students ( $p$ $=0.04$ ) and less than one year students and those who attended university for more than three years in their Intrinsic Stimulation ( $p=0.008)$.

The results obtained from analyzing the data showed that participants were moderate in their overall Academic Motivation $(N=156, M=56.89, S D=12.65)$. Gender did not reflect any difference between male and female participant neither in their overall AM nor any of the components of Academic Motivation $(p=0.521)$. Interviews also did not reveal any remarkable difference in the AM between male and female participants. Malaysian and international students were almost the same in their Academic Motivation $(p=0.612)$. There was a significant difference between Indian and Chinese students in their AM to know and to accomplish in learning English $(p=0.49)$ and between others and Chinese $(p=0.037)$. The implications of another study conducted in the American context demonstrated that Academic Motivation was largely based on the social context in which a person lives and whether an individual views himself independent or controlled by that context (Randazzo-McGough, 2000).

\section{Conclusion and Recommendations}

This study investigated Malaysian trainee teachers Academic Motivation to learn English The results of data analysis revealed that Malaysian trainee teachers in the present study were moderate in their Academic Motivation. There was no difference between participants in terms of gender or nationality. There was a significant difference in Intrinsic Academic Motivation to know between Indians and Chinese. Based on the specialization, there were significant differences between SNE and TESL, DECE and ECE respectively in the level of Amotivation. In other words, SNE and ECE were the least amotivated groups. TESL and SNE were the most intrinsically motivated among all courses. DECE were the most externally introjected in their motivation. TESL participants were the most externally regulated. Participants who spent more than three years, three years and two years were significantly higher in Intrinsic Academic Motivation than those who spent less than one year in the Faculty of Education.

The results of the current study highly recommend that greater concern to be given to cultural and individual factors that affect Academic Motivation to learn English. Lecturers should understand the diversity in the factors affecting Academic Motivation to learn English. Driven by the results of the present study Academic Motivation to learn English plays an important role in English language learning and the following recommendations can be considered:

First, screening trainee teachers' cognitive abilities, attitudes about self and university, as well as their language skills when they first come to the Faculty of Education is the key to understanding their abilities and limitations. This screening process could be repeated every year to compare the results with previous screening to make decisions about the suitability of the current content introduced to trainee teachers.

Second, providing more opportunities for students to use English can be achieved by changing classroom environment, teaching techniques, encouraging trainee teachers to participate in different activities outside the classrooms like English language clubs, journeys to native speaking countries, debates, drama, songs and free writing competitions.

Third, stronger relationships with parents can help better understand any changes that may take place away from university. An orientation programme may be helpful to update parents with the nature of the study of their sons and daughters and what can be done to help all achieve the desired outcomes.

Fourth, it is important to link the choice of applicants to the Faculty of Education to be among the best performers in the national assessment tools like (SPM) to ensure the quality of future teachers. As researchers argue that there is a strong correlation between teacher competence and their students' performance.

Finally, it is suggested to make use of new features in Learning Management Systems (LMS) that allow lecturers to start a topic and invite students to discuss by writing, sending voice messages and short videos of themselves. Giving them the chance to express may encourage them to show their best performance as these social media is noticed to part of their daily life. 


\section{Acknowledgment}

I would like to express my sincere gratitude to Prof. Dr Mogana Dhamotharan for her intellectual and emotional support. Furthermore, my warmest thanks go to Ms Lydia Foong, Head of the Faculty of Education, SEGi University. I would also like to thank Dr Palanisamy Veloo and Dr Shaheen Mansori and Dr Muhammad Farrukh Iqbal who provided support and assistance to me during my study by sharing their statistical knowledge and insights. I also greatly appreciate the assistance from the faculty and students at SEGi University. It would have been difficult to conduct this study without their willingness and precious help throughout the data collection process. Finally, my greatest sincere thanks go to my family for their love and unconditional support during my academic career. I would like to thank my beloved wife Reda and my son Mohamed, uncles and aunts, sisters and brother for their precious support. Without their support, I would never be able to reach where I am today. Finally, Many thanks to my best friend ever Mr. Mohamed Kudaish for his endless support.

\section{Ethics}

This article is original and contains unpublished material. The corresponding author confirms that all of the other authors have read and approved the manuscript and no ethical issues involved.

\section{References}

Choi, P.L., 2008. Cross-border choice as identity investment: Cases of Malaysian and Indonesian ethnic Chinese students in Hong Kong. Int. J. Educ. Reform, 17: 270-290.

Covington, M.V., 2000. Goal theory, motivation and S chool a chievement: An integrative review. Annual Rev. Psychol., 51: 171-200.

DOI: 10.1146/annurev.psych.51.1.171

Crookes, G. and R.W. Schmidt, 1991. Motivation: Reopening the research agenda. Language learning.

Deci, L., 1975. Intrinsic motivation. Plenum Publishing Co., New York.

Deci, E.L. and R.M. Ryan, 1985. Conceptualizations of Intrinsic Motivation and Self-Determination. In: Intrinsic Motivation and Self-Determination in Human Behavior, Deci, E.L. and R.M. Ryan (Eds.), Springer, pp: 11-39.

Deci, E.L. and R.M. Ryan, 2000. The "What" and "Why" of goal pursuits: Human needs and the selfdetermination of behavior. Psychol. Inquiry, 11: 227-268. DOI: 10.1207/S15327965PLI1104_01

Dornyei, Z., 1994. Motivation and motivating in the foreign language classroom. Modern Lang. J., 78: 273-284. DOI: 10.1111/j.1540-4781.1994.tb02042.x
Eccles, J.S., 1983. Expectancies, values and academic behaviors. In: Achievement and Achievement Motives: Psychological and Sociological Approaches, Spence, J.T. (Ed.), W.H. Freeman, pp: 76-146.

Gagné, M. and E.L. Deci, 2005. Self-determination theory and work motivation. J. Organiz. Behav., 26: 331-362. DOI: 10.1002/job.322

Gardner, R.C. and W.E. Lambert, 1972. Attitudes and motivation in second language learning. Lang. Learn., 76: 348-355.

Gill, S.K., 2005. Language policy in Malaysia: Reversing direction. Lang. Policy, 4: 241-260.

DOI: $10.1007 / \mathrm{s} 10993-005-7859-9$

Ida Fatimawati, A.B., 2012. A study on the relationship between Malaysian learners' self-concept in Academic writing and their engagement.

Jou, Y.S., 2012. Sociolinguistic approaches to identity negotiation and language learning: A circumstantiality perspective on communities of practice. Int. J. Res. Stud. Lang. Learn., 2: 49-60. DOI: $10.5861 /$ ijrsll.2012.105

Kaplan, A. and M.L. Maehr, 2007. The contributions and prospects of goal orientation theory. Educ. Psychol. Rev., 19: 141-184. DOI: 10.1007/s10648-006-9012-5

Law of Malaysia, 2006. Private higher educational institutions act 1996. Law of Malaysia.

Mahady, 2010. Corpus linguistics based error analysis of first year Universiti. Atlantic.

Masgoret, A.M. and R.C. Gardner, 2003. Attitudes, motivation and second language learning: A metaanalysis of studies conducted by Gardner and associates. Lang. Learn., 53: 167-210. DOI: $10.1111 / 1467-9922.00227$

Maslow, 1970. Motivation and personality.

Randazzo-Mcgough, C., 2000. Ethnic identity, personality and academic achievement: A study of cultural and psychological factors affecting success in college. California School of Professional Psychology.

MGBSLN, 2015. Room for improvement | New Straits Times | Malaysia General Business Sports and Lifestyle News.

Rubenfeld, S., L. Sinclair and R. Clément, 2007. Second language learning and acculturation: The role of motivation and goal content congruence. Canad. J. Applied Linguist., 10: 309-323.

Ryan, R.M. and E.L. Deci, 1989. Bridging the research traditions of task/ego involvement and intrinsic/extrinsic motivation: Comment on Butler (1987). J. Educ. Psychol., 81: 265-268. DOI: $10.1037 / 0022-0663.81 .2 .265$

Ryan, R. and E. Deci, 2000. Intrinsic and extrinsic motivations: Classic definitions and new directions. Contemporary Educ. Psychol., 25: 54-67.

DOI: $10.1006 /$ ceps. 1999.1020 
Stover, J.B., G. de la Iglesia, A.R. Boubeta and M.F. Liporace, 2012. Academic motivation scale: Adaptation and psychometric analyses for high school and college students. Psychol. Res. Behav. Manage., 5: 71-83. DOI: 10.2147/PRBM.S33188

Thrash, T.M. and A.J. Elliot, 2002. Implicit and selfattributed achievement motives: concordance and predictive validity. J. Personality, 70: 729-755.

DOI: $10.1111 / 1467-6494.05022$
Vansteenkiste, M., W. Lens and E.L. Deci, 2006. Intrinsic versus extrinsic goal contents in selfdetermination theory: Another look at the quality of academic motivation. Educ. Psychol., 41: 19-31. DOI: $10.1207 /$ s15326985ep4101_4 